\title{
Comment
}

\section{Mexico - Antidumping Measures on Rice}

\section{Prepared for the ALI Project on the Case Law of the WTO}

\author{
CLAUDIO DORDI \\ Professor of International Law, Bocconi University, Milan
}

\section{The main issues raised in the paper}

This commentary deals with two of the main issues raised in the paper presented by Mavroidis and Sapir, as follows:

1. The consequences following the Appellate Body $(\mathrm{AB})$ interpretation of the term 'known exporter or producer ... of the product under investigation' contained in Article 6.10 of the AD Agreement;

2. Some shortcomings of the AD Agreement, and in particular the one identified in Section 4 of the paper of the authors, where Mavroidis and Sapir point out that while '[d]umping is a pricing strategy whereby producers in one country charge lower prices in foreign markets than in their home market', Article $2 \mathrm{AD}$ 'defines dumping in terms of countries with no reference to individual firms'.

\section{The consequences following the $A B$ interpretation of the term 'known'}

It is worthwhile to summarize, first of all, the rationale of the two authors' point of view regarding the interpretation of the term 'known' in Articles 6.10 and 12.1 of the AD Agreement, as follows:

1. The AD Agreement lacks precision as it does not contain any provisions aimed at determining:

(a) The extension of the powers mandated to the AD investigating authority in identifying the 'known' exporters;

(b) The treatment to be reserved, during $\mathrm{AD}$ proceedings, to the third category of exporters identified by the Agreement, the so-called 'unknown exporters'. 
2. The AB, in interpreting the term 'known', did not manage to come up with a reasonable construction of the AD Agreement, as:

(a) It applied a 'completely textual' interpretation of Article 6.10, holding that the term 'known exporters' appearing in Article 6.10 does not include exporters that the investigating authority should have known, but did not know, at the time when the investigation was initiated:

(b) The above-mentioned interpretation has the effect of widening the class of unknown exporters, and, as a consequence, the impact of duties imposed on this class.

The divergent interpretation of the term 'known' provided by the Panel and by the Appellate Body reflects a different conception of AD proceedings and of the nature of the $\mathrm{AD}$ investigating authority powers. As recognized in many WTO member States, the AD investigating authority is the administrative body responsible for the application of the rules and regulations on antidumping duties and countervailing measures. Normally, investigations by administrative agencies or officials have no parties as found in a lawsuit or criminal prosecution, and, usually, there is no need to give notice of the investigation. However, de facto, investigations of the $\mathrm{AD}$ authorities are 'against' some exporters and end with a penalty (the AD duties) imposed on specific products manufactured by enterprises located in a definite country. Moreover, the AD Agreement provides specific burdens for the investigating authority regarding the notice of the investigation. Therefore, the WTO AD proceeding is a sort of hybrid standing in the middle between a lawsuit and an administrative proceeding.

Nevertheless, the Mexico-Antidumping Measures on Rice reveals the radical, and opposite, point of view of the Panel and the Appellate Body regarding the nature of $\mathrm{AD}$ proceedings and the features of $\mathrm{AD}$ investigating powers.

According to the 'extensive interpretation' of the Panel, which is shared by the two authors, the investigating authority, when conducting an investigation, cannot remain entirely passive and must inform those interested parties of which it can reasonably obtain knowledge. ${ }^{1}$ As a consequence, the term 'known exporter or producer' in Article 6.10 refers to the exporters or producers of which 'an objective and unbiased investigating authority properly establishing the facts and conducting an active investigation could have and should have reasonably been considered to have [obtained] knowledge'. ${ }^{2}$ According to this line of thinking, the nature of the powers of $\mathrm{AD}$ investigating authority is similar to that of the administrative agencies above mentioned. 
However, this interpretation cannot be satisfactory from a legal point of view as:

- it does not eliminate the category of 'unknown exporters' who were exporting during the period of investigation but have not been identified;

- the fact that, as pointed out by the authors, 'this category would probably be insignificant' cannot be considered as a welcomed result, in particular when the products under investigation are manufactured by many small and medium enterprises;

- there are no indications in the AD Agreement about the possibility to extend the treatment provided for all 'new shipments' to 'unknown' exporters. The AD Agreement, as it stands, 'does not specifically deal with the case of exporters who can ... hide during the investigation process'.

The Appellate Body, on the contrary, held that the term 'known exporters' appearing in Art. 6.10 $\mathrm{AD}$ does not include exporters that the investigating authority should have known, but did not know, at the time when the investigation was initiated. According to the authors, the AB followed a 'completely textual' interpretation of Art. 6.10 AD.

It should be pointed out, however, that the interpretation of the $\mathrm{AB}$ cannot be qualified as either 'restrictive' or 'completely textual' if we adopt, as a benchmark, the frame of a 'lawsuit' or a 'criminal prosecution' proceeding. Normally, before the courts, 'known' persons are those involved in the procedure because they either have been formally summoned or they have decided voluntarily to participate in the trial. The term 'known' is a qualified term that has a common meaning in the procedural law of most of the countries of the international community: it is a sort of 'general principle of law', as specified in Article 38 of the International Court of Justice Statute. The term 'known' has not a 'substantive meaning' (i.e. how many persons are known in a generic way) but a 'formal meaning' (i.e. how many persons are formally involved in the procedure). As a consequence, 'known' is a fact for the court and not a result that must be obtained with an investigation.

The consequences following from the above-mentioned interpretation of the term 'known' by the $\mathrm{AB}$ should be evaluated in connection with the fact that, according to the $\mathrm{AB}$, the duty to be paid by unknown exporters cannot be based on 'facts available.' According to the $\mathrm{AB}$, an authority that imposes a duty on unidentified exporters based on facts available, including facts from the petition, is acting in violation of Article 6.8 and paragraph 1 of Annex II. The implications of the above-mentioned statement have been clearly described by the authors:

According to the $\mathrm{AB}$, putting exporters on notice that facts available will be used is a precondition for the use of facts available. This condition, for obvious reasons, can never be met in the case of unidentified exporters: one cannot notify the person that has not been identified. 
The $\mathrm{AB}$ addressed a situation in which the residual rate was based on petitioner data, and was particularly adverse when compared to the margins of dumping calculated for the examined (known) exporters. But the need to inform exporters of the fact that, in the absence of cooperation, facts available will be used, applies in all cases, and not only when the data used is provided by the petitioner. To a certain extent, any margin based on information other than data provided by the exporter itself is based on 'facts available.' Logically speaking, the AB's statement could thus be read to imply that no residual duty can be imposed on such unknown exporters. A rate based on the highest margin of an exporter individually calculated, as is the EC's practice, is also a facts-available rate for the noninvestigated exporter, and hence, in this line of thinking, would, as well, be WTO-inconsistent. ${ }^{3}$

The authors criticized the above-mentioned reasoning stating that if:

all the $\mathrm{AB}$ wanted to say was that facts available which are adverse may not be used to calculate a duty for unknown exporters', '[ $t$ ] here remains a serious problem: when is the use of facts available (not) adverse? Is a residual duty based on the highest margin found for an investigated exporter less adverse than the use of information contained in the petition?'

The criticisms formulated by the authors can be shared only partially. Article 6.8 and paragraph 1 of Annex II, in fact, contain 'due process' provisions. 'Due process' rules provide normally 'procedural rights' guaranteeing fundamental fairness, justice, and liberty, and they do not deal with the substance of the rule. In the situation above mentioned, for example, it is not relevant for the due process provisions whether 'facts available' are adverse for the exporters. The simple fact that the exporters have not been notified of specific information by the investigating authority is a sufficient element impeding the investigating authority to utilize such information: i.e. it is not important whether the 'facts available' are adverse for the exporters. This is a principle that is common to most of the national legal systems.

Anyhow, the $\mathrm{AB}$ interpretation of the term 'known', combined with the preclusion of utilizing the 'facts available' in the application for the initiation of the investigation against an exporter that was not given notice of the information the investigating authority requires, carry some important consequences, such as the following:

- Even if the investigating authority, when conducting an investigation, is not obliged to be 'active' (i.e. informing those interested parties of which it can obtain knowledge), it is de facto forced to behave in a proactive manner, as it is not anymore possible to apply antidumping duties towards 'unknown' exporters based on 'facts available' (this means, in practice, that it is not possible to apply antidumping duties against unknown exporters!). The

3 Mavroidis and Sapir, Section 2.3. 
higher the number of exporters identified, the larger the possibility to utilize 'facts available' for calculating dumping margins for noncooperative exporters;

- The investigating authority maintains its features of 'hybrid' entity, between a prosecutor and a court;

- In the EC, the AB interpretation is consistent with Article 41.2 of the Charter of Fundamental Rights, which guarantees 'the right of every person to be heard, before any individual measure which would affect him or her adversely is taken', and 'the right of every person to have access to his or her file, while respecting the legitimate interests of confidentiality and of professional and business secrecy.'

\section{Incongruences in AD Agreement}

Another interesting issue raised by the two authors is that while dumping is a practice of firms, the AD Agreement defines dumping in terms of countries with no reference to individual firms (Article 2 AD). Moreover, the authors highlighted that the AD Agreement is internally inconsistent from an economic point of view, as '[o]n the one hand', it 'supposes that all exporters or producers of an allegedly dumped product who produce in the country in question are potentially guilty of injurious dumping in the importing country. On the other, it recognizes that different exporters or producers may behave differently and should therefore be subject to different treatment in terms of $\mathrm{AD}$ duties.'

We will try to provide a valid explanation justifying the above-mentioned incongruency of the AD Agreement.

As Sapir pointed out (in another writing):

Dumping can only occur if two conditions are fulfilled. First, the industry must be imperfectly competitive, so that firms have market power. That is firms must be able to set prices in the domestic or foreign market rather than take prices as given in both markets. Second, markets must be segmented, so that domestic customers cannot easily purchase products sold at a lower price in foreign markets. Dumping is considered an unfair practice in international trade. $^{4}$

However, the absence of a national competition policy may be a factor favoring the increase of the market power of a group of companies in a specific country. That's why many authors justify antidumping as a protective measure aimed at coping with the differences existing in national competition laws and in the regulatory standard between States. 
Other authors have a more general view and consider that dumping can occur because of the differences existing between 'different economic standards'. J. Jackson, for example, stated:

As world economic interdependence has increased, it has become more difficult to manage relationships among various economies. This problem is analogous to the difficulties involved in trying to get two computers of different designs to work together. To do so, one needs an 'interface' mechanism to mediate between the two computers. Likewise in international economic relations, particularly in trade, some 'interface mechanism' may be necessary to allow different economic systems to trade together harmoniously. ${ }^{5}$

Moreover, the segmentation of the market (the second condition identified by Sapir as a prerequisite of dumping) can be obtained by raising barriers to trade limiting the import of foreign goods. As a consequence, companies in countries where the competition is not particularly protected from abuses and where there are high import barriers, potentially have more possibility to dump products in other markets than companies located in countries where the competition is strictly regulated and with lower barriers to import. Of course, this conclusion is not always valid, as in the case of AD duties applied against shrimps originating in countries with thousands of enterprises producing shrimps.

\section{Some suggestions}

From our point of view, the paper of Mavroidis and Sapir raises two interesting problems:

1. What are the instruments that can be utilized to reduce the number of 'unknown' exporters in AD proceedings?

2. Is it possible to limit AD duties only to enterprises that really dump products?

In regard to question 1 , we think that there is a need to restructure the institutional system of AD in importing countries; the investigating authority should be separated from the agency empowered to impose AD duties. A procedure closer to a criminal proceeding (with the investigating authority as a 'prosecutor' and with a sort of court empowered with the right to decide whether to impose AD duties) would solve the problem of 'passive' investigating authorities (and the problem of 'unknown' exporters).

With regard to question 2, there should be a modification in the definition of 'dumping'. Moreover, the definition of 'injurious dumping' could be limited to enterprises exporting from countries not adequately regulating competition and with high barriers to import.

5 Jackson, World Trade and the Law of GATT, 1997, p. 248. 